\title{
Impact of type 2 diabetes mellitus on the prognosis of early stage triple-negative breast cancer in People's Republic of China
}

This article was published in the following Dove Press journal:

OncoTargets and Therapy

27 November 2014

Number of times this article has been viewed

Fang-Jing $\mathrm{Ma}^{\mathrm{I}-3, *}$

Zhe-Bin Liu ${ }^{1,2, *}$

Li Qu ${ }^{4, *}$

Shuang Hao ${ }^{1,2}$

Guang-Yu Liu ${ }^{1,2}$

jiong $\mathrm{Wu}^{1,2}$

Zhi-Ming Shao ${ }^{1,2}$

'Department of Breast Surgery, Key Laboratory of Breast Cancer in

Shanghai, Fudan University Shanghai

Cancer Center, ${ }^{2}$ Department of

Oncology, Shanghai Medical College,

Fudan University, Shanghai, People's

Republic of China; ${ }^{3}$ Department

of Breast Surgery, First Affiliated

Hospital of Xinjiang Medical

University, Urumqi, Xinjiang Uygur

Autonomous Region, Xinjiang,

People's Republic of China;

${ }^{4}$ Department of General Surgery,

Zhejiang Hospital, Hangzhou, People's

Republic of China

*These authors have contributed equally to this work
Correspondence: Guang-Yu Liu Department of Breast Surgery, Shanghai Cancer Center, Shanghai Medical College, Fudan University, 270 Dong An Road, Shanghai 200032, People's Republic of China

Email liugy123@yahoo.com
Background: Type 2 diabetes mellitus (T2DM) is one of the most common chronic metabolic diseases. Increased cause-specific mortality and decreased disease-free survival (DFS) have been reported among cancer patients with T2DM compared with patients without T2DM, even after adjustments of other comorbidities. However, less is known about the impact of T2DM and other comorbidities on DFS in Chinese patients with early stage triple-negative breast cancer (TNBC).

Patients and methods: We assessed patients who were newly diagnosed with early stage primary TNBC at the Department of Breast Surgery, Fudan University, from 2003 to 2011. Of the 1,100 TNBC patients, 865 female patients had invasive and early stage TNBC. The association of the variables in the T2DM and non-T2DM groups was compared using the Pearson's chi-square and independent $t$-tests. DFS was estimated using the Kaplan-Meier method. The effects of T2DM and other possible risk factors on DFS were assessed by Cox proportional hazards regression using univariate or multivariate analysis.

Results: A total of 865 early stage primary TNBC cases were studied, including $104(12.02 \%)$ subjects with T2DM. Metastatic or recurrent disease was detected in $24(23.08 \%)$ patients in the T2DM group and 35 (4.60\%) patients in the non-T2DM group. Patients with T2DM exhibited a significantly lower DFS than patients without T2DM (log-rank $P<0.001)$. Similar results were observed when patients with positive lymph nodes were compared with patients with negative lymph nodes ( $\log -\operatorname{rank} P=0.003)$. T2DM was independently associated with a lower DFS after adjustments of other variables (adjusted hazard ratio, 7.719; 95\% confidence interval, 4.304-13.843; $P<0.001$ ) and adjustments of lymph node positivity (adjusted hazard ratio, $2.407 ; 95 \%$ confidence interval, $1.391-4.166 ; P=0.002$ ). The DFS rates at 2 years for the T2DM group and the non-T2DM group were $78 \%$ and $97 \%$, respectively. The prognostic influence of T2DM was consistent across the subgroups, including subgroups by age $(>50$ or $\leq 50)$, menopausal status (post- or premenopausal), tumor size ( $>5 \mathrm{~cm}$ or $\leq 5 \mathrm{~cm}$ ), lymph node involvement (positive or negative), and adjuvant chemotherapy (received or not) using the Kaplan-Meier method (log-rank $P<0.05$ ).

Conclusion: In the People's Republic of China, T2DM is an independent prognostic risk factor that indicates an increased likelihood of recurrence and metastasis in patients with early stage TNBC. The presence of T2DM should be taken into account when evaluating the risk for an early stage TNBC patient. More effective therapeutic regimens are needed for early stage TNBC patients with T2DM.

Keywords: disease-free survival, hyperglycemia, highly aggressive breast cancer

\section{Introduction}

The People's Republic of China has one of the fastest growing rates of breast cancer in the world. In recent years, breast cancer incidence has increased at an annual rate 
of 3\% in the People's Republic of China, and breast cancer has become the most common cause of death among urban women. In many other countries also, breast cancer is a significant cause of death among women. ${ }^{1}$

Triple-negative breast cancer (TNBC) refers to a type of breast cancer that does not express estrogen receptors, progesterone receptors, or human epidermal growth factor receptor 2. Because of these characteristics, endocrine therapy and targeted therapy are not effective treatments for this highly aggressive form of breast cancer. ${ }^{2-4}$ Individuals with TNBC exhibit increased mortality compared with the individuals with other subtypes of breast cancer. ${ }^{5-7}$

Type 2 diabetes mellitus (T2DM) is one of the most common chronic metabolic diseases. This disease may result in serious conditions and has a poor prognosis. ${ }^{8,9}$ Malignant tumors may be associated with the chronic stimulation of high blood glucose to normal organs, which is induced by T2DM. As of 2008, 40\% of all T2DM patients in the world live in the People's Republic of China and India. T2DM is associated with many cancers, including breast cancer, ${ }^{10}$ pancreatic cancer, liver cancer, ${ }^{11-13}$ and bladder cancer. ${ }^{14}$ Increased cause-specific mortality and decreased diseasefree survival (DFS) rates have been reported among cancer patients with T2DM compared with patients without T2DM, even after adjustments of other comorbidities. ${ }^{15}$ Early stage breast cancer patients with T2DM in Asia $^{16}$ and America ${ }^{17}$ are also reported to exhibit a poor prognosis.

The incidence of T2DM is increasing rapidly in the Chinese population as a whole, and T2DM is therefore expected to be common among breast cancer patients. The impact of T2DM on breast cancer patients has been studied extensively, ${ }^{18-22}$ and the clinical characteristics of TNBC patients with T2DM have also been discussed. ${ }^{23}$ However, less is known about the effects of T2DM and other comorbidities on the DFS outcomes of Chinese patients with early stage TNBC.

Cancer treatment can be divided into three steps. Primary prevention is to eliminate or reduce possible carcinogenic factors and prevent the occurrence of cancer. Secondary prevention is to diagnose cancer in its early stage and treat it in a timely way. Tertiary prevention is to improve the quality of life, relieve the pain, and prolong the life. Secondary prevention of TNBC is as important as primary prevention. Therefore, we conducted this retrospective study to examine the influence of T2DM on the prognosis of early stage TNBC. If we can control the risk factors of poor prognosis in patients with TNBC, we can improve the survival and quality of life of these patients.

\section{Patients and methods}

\section{Ethics}

All samples were anonymously coded in accordance with local ethical guidelines, and written informed consent was obtained. This study was approved by the Review Board of Fudan University Shanghai Cancer Center and conforms to the principles outlined in the Declaration of Helsinki.

\section{Data source}

We assessed patients who were newly diagnosed with early stage primary TNBC at the Department of Breast Surgery, Shanghai Cancer Center (an affiliate of Fudan University) between 2003 and 2011. A total of 1,100 TNBC patients were identified histopathologically and treated. Of these, 235 patients had no follow-up data, and the remaining 865 female patients exhibited invasive early stage TNBC according to the criteria described by the World Health Organization (WHO) classification. T2DM and hypertension were diagnosed before the diagnosis of breast cancer, and all of these patients received standard treatment.

Diagnoses were based on the following criteria:

1. T2DM was diagnosed according to the WHO/International Diabetes Federation diagnostic criteria, which includes a fasting plasma glucose concentration greater than $7.0 \mathrm{mmol} / \mathrm{L}$, a random plasma glucose concentration greater than $11.1 \mathrm{mmol} / \mathrm{L}$, or a 2-hour plasma glucose concentration greater than $11.1 \mathrm{mmol} / \mathrm{L}$ during an oral glucose tolerance test.

2. Hypertension was diagnosed using the following criteria: 1) patients with a clear medical history of hypertension who had a history of using antihypertensive medications; 2) patients with hypertension diagnosed according to the October 1999 Hypertension Alliance guidelines, with reference to the $\mathrm{WHO} /$ International Society of Hypertension guidelines (ie, patients who had at least three systolic blood pressures [not taken on the same day] of at least $140 \mathrm{mmHg}$ and/or diastolic blood pressure measurements of at least $90 \mathrm{mmHg}$ under quiet conditions, using a standard measurement method); and 3) patients in whom the diagnosis of renal hypertension and other secondary causes of hypertension had been ruled out.

Among the TNBC patients, we collected the following variables from medical record review: age at the time of the first diagnosis of TNBC, menopausal status, tumor size, lymph node involvement, presence of lymphovascular invasion, histological grade, body mass index (BMI), blood pressure status, adjuvant chemotherapy status, and whether 
the patient had recurrent or metastatic disease or had died at the end of the follow-up period.

Other basic data, including the specific pathological type and lifestyle data, were not analyzed in the present study because this information was not available in some cases. Follow-up information was recorded from outpatient department records and personal contact with the patient via mail and phone calls.

\section{Statistical analyses}

DFS was defined as the time from the first diagnosis of breast cancer to the initial occurrence of disease relapse (local, regional, or distant). Patients without any evidence of relapse or death were censored at the last date they were known to be alive. The Statistical Package for the Social Sciences 18.0 software package (SPSS Inc., Chicago, IL, USA) was used for statistical analysis. Correlations among the variables in the T2DM and non-T2DM groups were determined using the Pearson's chi-square and independent $t$-tests. DFS durations were estimated using the Kaplan-Meier method and compared using the log-rank test. The effects of T2DM and other possible risk factors on DFS were assessed by Cox proportional hazards regression using univariate or multivariate analysis, via the adjusted hazard ratio (HR) and the associated $95 \%$ confidence interval $(95 \% \mathrm{CI})$.

Adjusted HRs in subgroups defined by age $(>50$ or $\leq 50$ years), tumor size ( $>5$ or $\leq 5 \mathrm{~cm}$ ), menopausal status (post- or premenopausal), lymph node involvement (positive or negative), and adjuvant chemotherapy status (chemotherapy or no chemotherapy) were determined to examine whether the effects of T2DM on DFS were consistent across different patient populations. A two-sided $P$-value $(P \leq 0.05)$ was considered statistically significant.

\section{Results}

\section{Demographics and clinical characteristics}

A total of 865 early stage primary TNBC cases were studied, including $104(12.02 \%)$ subjects with T2DM and $761(87.98 \%)$ subjects without T2DM. The demographic and clinical characteristics for the two groups are presented in Table 1. The median follow-up time for this study was 32.46 months (range 1-120 months). Compared with patients without T2DM, patients with T2DM were older (mean age, 56.91 years vs 50.48 years; $P<0.001$ ), more likely to be postmenopausal $(P<0.001)$, more likely to have hypertension $(P<0.001)$, more likely to have a $\mathrm{BMI} \geq 25(P=0.04)$, and more likely to use adjuvant chemotherapy $(P<0.001)$. Metastatic or recurrent disease
Table I Demographic and clinical characteristics of TNBC patients with and without T2DM

\begin{tabular}{|c|c|c|c|c|}
\hline Characteristic & $\begin{array}{l}\text { Non-T2DM } \\
(\mathrm{N}=76 \mathrm{I})\end{array}$ & $\begin{array}{l}\text { T2DM } \\
(N=104)\end{array}$ & $t / \chi^{2}$ & $P$-value \\
\hline \multicolumn{5}{|l|}{ Subgroups, N (\%) } \\
\hline \multicolumn{5}{|l|}{ Age, years } \\
\hline Mean & 50.48 & 56.91 & 31.087 & $<0.001$ \\
\hline SE & 11.003 & 11.292 & & \\
\hline \multicolumn{5}{|l|}{ Menopausal status } \\
\hline Premenopausal & $424(55.72)$ & $28(26.92)$ & 30.403 & $<0.001$ \\
\hline Postmenopausal & $337(44.28)$ & $76(73.08)$ & & \\
\hline Unknown & 0 & 0 & & \\
\hline \multicolumn{5}{|l|}{ Tumor size } \\
\hline$\leq 5 \mathrm{~cm}$ & $432(60.85)$ & $50(56.82)$ & 0.531 & 0.489 \\
\hline$>5 \mathrm{~cm}$ & $278(39.15)$ & $38(43.18)$ & & \\
\hline Unknown & 51 & 16 & & \\
\hline \multicolumn{5}{|c|}{ Lymph node involvement } \\
\hline Negative & $463(60.84)$ & $74(7 \mid .15)$ & 4.134 & 0.052 \\
\hline Positive & $298(39.16)$ & $30(28.85)$ & & \\
\hline Unknown & 0 & 0 & & \\
\hline \multicolumn{5}{|c|}{ Lymphovascular invasion } \\
\hline Negative & $617(81.08)$ & $79(75.96)$ & 1.523 & 0.235 \\
\hline Positive & $144(18.92)$ & $25(24.04)$ & & \\
\hline Unknown & 0 & 0 & & \\
\hline \multicolumn{5}{|l|}{ Histological grade } \\
\hline $\mathrm{I}-2$ & $289(45.02)$ & $36(46.15)$ & 0.036 & 0.904 \\
\hline 3 & $353(54.98)$ & $42(53.85)$ & & \\
\hline Unknown & 119 & 26 & & \\
\hline \multicolumn{5}{|l|}{ BMI } \\
\hline$<25$ & $460(61.17)$ & $51(50.00)$ & 4.663 & 0.04 \\
\hline$\geq 25$ & $292(38.83)$ & $51(50.00)$ & & \\
\hline Unknown & 9 & 2 & & \\
\hline \multicolumn{5}{|l|}{ Hypertension } \\
\hline No & $64 I(84.23)$ & $69(67.00)$ & $|8.4| \mid$ & $<0.001$ \\
\hline Yes & $120(15.77)$ & $34(33.00)$ & & \\
\hline Unknown & 0 & I & & \\
\hline \multicolumn{5}{|c|}{ Adjuvant chemotherapy } \\
\hline No & $419(55.06)$ & $28(26.92)$ & 29.005 & $<0.001$ \\
\hline Yes & $342(44.94)$ & $76(73.08)$ & & \\
\hline Unknown & 0 & 0 & & \\
\hline \multicolumn{5}{|c|}{ Recurrence or metastasis } \\
\hline No & $726(95.40)$ & $80(76.92)$ & 49.152 & $<0.001$ \\
\hline Yes & $35(4.60)$ & $24(23.08)$ & & \\
\hline Unknown & 0 & 0 & & \\
\hline
\end{tabular}

Abbreviations: TNBC, triple-negative breast cancer; T2DM, type 2 diabetes mellitus; SE, standard error; BMI, body mass index.

occurred in $24(23.08 \%)$ patients in the T2DM group and $35(4.60 \%)$ patients in the non-T2DM group at the end of the follow-up period. It was not possible to determine the overall survival rates, as the mortality rates were low: $3(0.40 \%)$ patients in the non-T2DM group died and $0(0 \%)$ patients in the T2DM group died. Tumor size, lymph node involvement, presence of lymphovascular invasion, and histological grade did not differ significantly between the two study groups. 


\section{Clinical outcomes}

1. DFS for TNBC patients by T2DM and lymph node status: Patients with T2DM exhibited a significantly lower DFS rate than patients without T2DM (Figure 1; $P<0.001)$. Similar results were observed when patients with positive lymph nodes were compared with patients with negative lymph nodes (Figure 2; $P=0.003$ ). The DFS rates at 2 years for patients with and without T2DM were $78 \%$ and $97 \%$, respectively. The DFS rates at 2 years for patients with positive and negative lymph nodes group were $93 \%$ and $96 \%$, respectively.

2. Univariate analysis of potential factors predicting DFS for TNBC patients: When risk factors predicting DFS for TNBC patients were considered individually, age $>50$, high blood sugar levels, postmenopausal status, positive lymph node involvement, and adjuvant chemotherapy all appeared to be associated with lower DFS rates $(P<0.05$; Table 2$)$.

3. Multivariate analysis of potential factors predicting DFS for TNBC patients: To verify that the potential risk factors were independent, we performed a multivariate analysis including factors that were significant in univariate analysis as well as another important risk factor, tumor size. After adjusting for age, blood sugar level, menopausal status, tumor size, lymph node involvement, and adjuvant chemotherapy status in the multivariate analysis, T2DM remained an independent predictor of lower DFS (Table 3; adjusted HR, 7.719; 95\% CI, 4.304-13.843; $P<0.001)$. Positive lymph node status also was an independent predictor of poor DFS (adjusted HR, 2.407; 95\% CI, 1.391-4.166; $P=0.002$ ).

4. Subgroup analysis: Furthermore, we wanted to investigate how T2DM affected each subgroup of interest using the

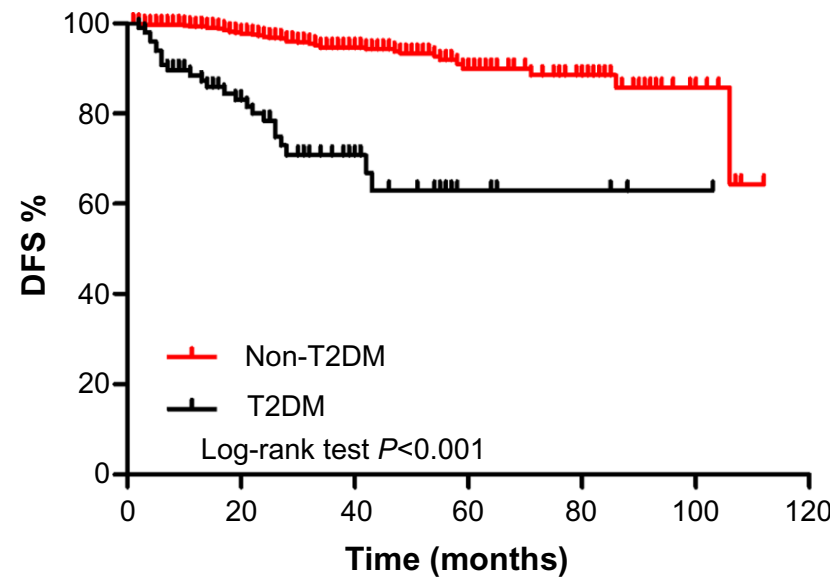

Figure I Kaplan-Meier estimates of DFS for TNBC patients with and without T2DM. Abbreviations: DFS, disease-free survival; TNBC, triple-negative breast cancer; T2DM, type 2 diabetes mellitus.

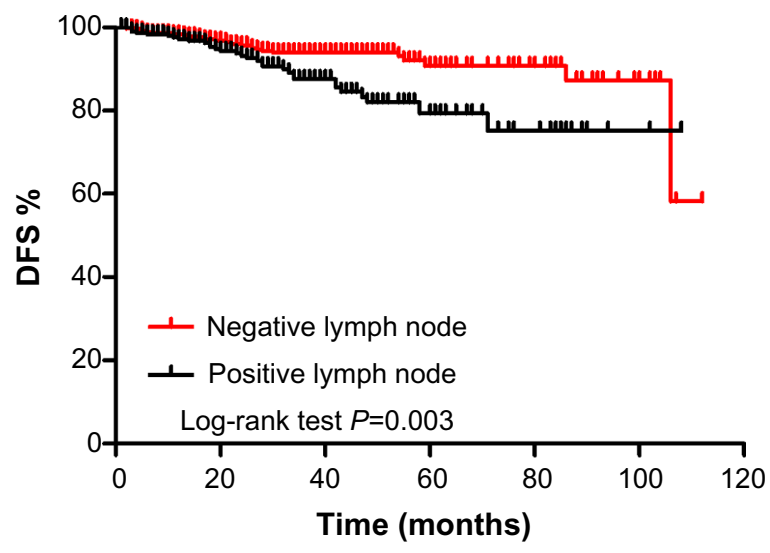

Figure 2 Kaplan-Meier estimates of DFS for TNBC patients according to the lymph node involvement status.

Abbreviations: DFS, disease-free survival; TNBC, triple-negative breast cancer.

Kaplan-Meier method. These results revealed that the negative influence of T2DM on prognosis was consistent across the following subgroups (log-rank $P<0.05$ ), including patients with age $>50$ or $\leq 50$ (Figure $3 \mathrm{~A}$ and $\mathrm{B}$ ), tumor size $>5 \mathrm{~cm}$ or $\leq 5 \mathrm{~cm}$ (Figure $3 \mathrm{C}$ and D), postmenopausal or premenopausal patients (Figure 3E and F), patients with positive and negative lymph nodes (Figure $3 \mathrm{G}$ and $\mathrm{H}$ ), and patients who either received or did not receive adjuvant chemotherapy (Figure 3I and J). Multivariate analysis also verified these results and demonstrated that the ranges of the adjusted HRs were 3.525-19.086 for DFS in these groups, as shown in Table 4.

\section{Discussion}

Intensive research on the diagnosis and prognosis of patients with breast cancer has been ongoing for some time.

Table 2 Univariate analysis of potential factors predicting DFS for TNBC patients

\begin{tabular}{|c|c|c|c|}
\hline \multirow[t]{2}{*}{ Variables } & \multicolumn{3}{|l|}{ DFS } \\
\hline & $P$-value & HR & $95 \% \mathrm{Cl}$ \\
\hline Age $>50$ & 0.033 & 1.787 & $1.048-3.049$ \\
\hline Postmenopausal & 0.017 & 1.886 & $1.120-3.177$ \\
\hline Tumor size $>5 \mathrm{~cm}$ & 0.208 & 1.417 & $0.824-2.437$ \\
\hline Positive lymph node & 0.004 & 2.134 & $1.279-3.562$ \\
\hline \multicolumn{4}{|l|}{ involvement } \\
\hline T2DM & $<0.001$ & 6.809 & $4.022-11.526$ \\
\hline Adjuvant chemotherapy & 0.010 & 2.000 & I. $183-3.38 \mid$ \\
\hline Presence of & 0.211 & 1.506 & $0.793-2.859$ \\
\hline \multicolumn{4}{|l|}{ lymphovascular invasion } \\
\hline Histological grade $\geq 3$ & 0.716 & 0.893 & $0.487-1.640$ \\
\hline $\mathrm{BMI} \geq 25$ & 0.448 & 1.223 & $0.727-2.057$ \\
\hline Hypertension & 0.070 & 1.724 & $0.957-3.106$ \\
\hline
\end{tabular}

Note: Bold values denote $P \leq 0.05$.

Abbreviations: DFS, disease-free survival; TNBC, triple-negative breast cancer; $\mathrm{HR}$, hazard ratio; $\mathrm{Cl}$, confidence interval; T2DM, type 2 diabetes mellitus; BMI, body mass index. 
Table 3 Multivariate analysis of potential factors predicting DFS for TNBC patients

\begin{tabular}{|c|c|c|c|}
\hline \multirow[t]{2}{*}{ Variables } & \multicolumn{3}{|l|}{ DFS } \\
\hline & $P$-value & HR & $95 \% \mathrm{Cl}$ \\
\hline Age $>50$ & 0.967 & 1.021 & $0.393-2.651$ \\
\hline Postmenopausal & 0.691 & 2.166 & $0.048-97.518$ \\
\hline Tumor size $>5 \mathrm{~cm}$ & 0.093 & 1.605 & $0.925-2.784$ \\
\hline Positive lymph node involvement & 0.002 & 2.407 & $1.391-4.166$ \\
\hline T2DM & $<0.001$ & 7.719 & $4.304-13.843$ \\
\hline Adjuvant chemotherapy & 0.838 & 0.667 & $0.014-32.828$ \\
\hline
\end{tabular}

Note: Bold values denote $P \leq 0.05$.

Abbreviations: DFS, disease-free survival; TNBC, triple-negative breast cancer; $\mathrm{HR}$, hazard ratio; $\mathrm{Cl}$, confidence interval; T2DM, type 2 diabetes mellitus.

Clinicians have evaluated patient prognosis and the efficacy of treatment using histology, lymph node status, immune histochemical staining, and genetic analyses. However, due to the variable clinical manifestations of breast cancer treatment and the variable effects of different treatments, the aforementioned indicators alone cannot completely predict prognosis and outcomes. More indicators are needed to assist in systematic assessments. Variations in histology and the tumor microenvironment play important roles during tumor formation. Some diseases may induce microenvironment changes, such as an increase in growth factors, to increase the risk of recurrence and metastasis. We, therefore, performed this retrospective analysis to examine the prognosis of patients with T2DM and TNBC. The present study demonstrated that T2DM is an independent predictor of worse DFS in Chinese patients with early stage TNBC.

This is the first study to investigate the association between T2DM and DFS in a Chinese population with early stage TNBC. Although previous studies have also reported that T2DM is associated with worse cancer outcomes, including higher mortality, recurrence, and metastasis rates, ${ }^{24-27}$ the particular influence of T2DM on early stage TNBC has not been established, because these prior studies did not specifically focus on this patient group.

This retrospective study demonstrated that T2DM is an independent predictor of poor DFS in Chinese patients with early stage TNBC; however, the mechanism underlying this finding is unclear. A new study suggests that high insulin levels and insulin resistance increase the risk of breast cancer and indicate poor prognosis in patients with breast cancer. T2DM can promote the development of breast cancer by altering the insulin-like growth factor (IGF) and insulin signaling pathways. ${ }^{28}$ The first step in the activation of the insulin pathway is the interaction of insulin with the insulin receptor (IR). The IR plays an important role in activating the insulin pathway in breast cancer and its overexpression can induce the malignant transformation of mammary gland epithelial cells. Therefore, in subsequent studies, we will further investigate IGF and IR.

There is a confirmed relationship between T2DM and an increased incidence of breast cancer. ${ }^{29-32}$ In our study, the proportion of patients with T2DM was $12.02 \%$, which is similar to prior reports. T2DM generally occurs among older, postmenopausal women with other comorbidities such as hypertension and obesity. In the present study, patients with T2DM were older $(P<0.001)$, more likely to be postmenopausal $(P<0.001)$, more likely to exhibit hypertension $(P<0.001)$, and more likely to be obese $(P=0.04)$ compared with patients without T2MD. There were a greater number of patients with recurrent or metastatic disease in the T2DM group $(P<0.001)$. In addition to T2DM, age $(>50)$, postmenopausal status, lymph node positivity, and the use of adjuvant chemotherapy might also contribute to the prognosis of early stage TNBC patients. Although old age and postmenopausal patients represented a large proportion of the patients in the T2DM group, they were not independent prognostic factors for DFS. Only T2DM and the presence of lymph node involvement were independent prognostic factors. Positive lymph node status has been confirmed as an independent risk factor for worse DFS and overall survival (OS) in almost all types of breast cancer, ${ }^{33-35}$ especially in patients with TNBC. ${ }^{36}$ However, in the present study, we were not able to analyze the specific lymph node classification because of lack of data. Because of the characteristics of TNBC, the patients in this study received similar treatment, without endocrine or targeted therapy, which may explain why age $(>50)$ and postmenopausal status were not independent risk factors for lower DFS when we adjusted for other demographics and clinical characteristics. Tumor size, ${ }^{33-35}$ histological grade, ${ }^{33-35} \mathrm{BMI},{ }^{37-40}$ and blood pressure have been demonstrated to be correlated with DFS in early stage breast cancer. However, in the present study, we did not observe a significant correlation between these clinical factors and DFS. Several factors may explain this discrepancy. First, the study was highly selective, and patients with T2DM tended to be older; thus, other factors may have influenced prognosis in this group of patients. Second, the sample size may have limited our analysis. Finally, the data we gathered were somewhat limited, and there was some missing information. Furthermore, the prognostic influence of T2DM was consistent across almost all subgroups, including patients with age $>50$ or $\leq 50$, patients with tumor size $>5 \mathrm{~cm}$ or $\leq 5 \mathrm{~cm}$, postmenopausal and premenopausal patients, patients with positive and negative lymph nodes, and patients who either did or did not receive adjuvant chemotherapy. 
A

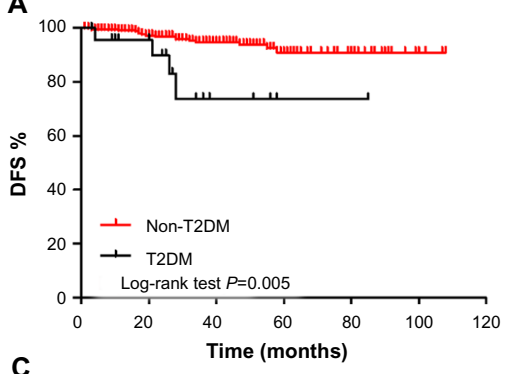

C

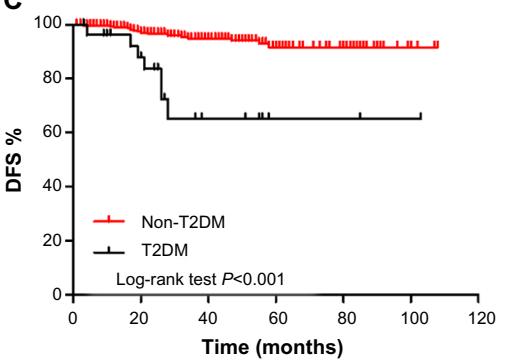

E

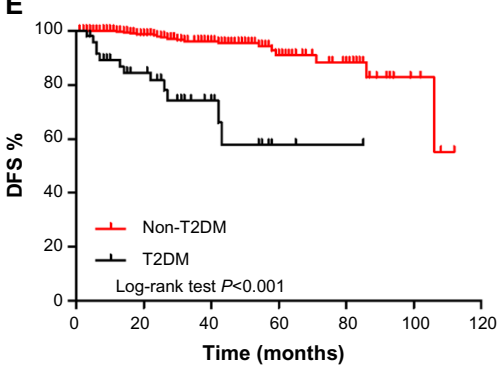

G

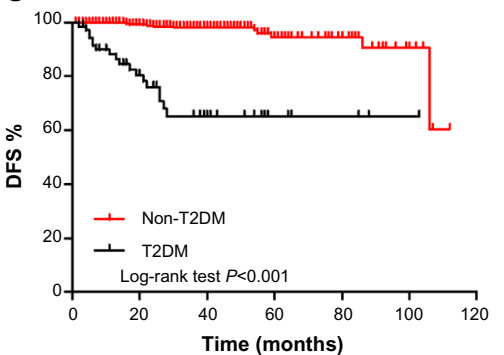

I

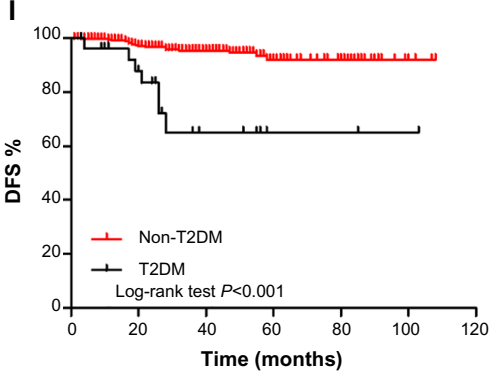

B

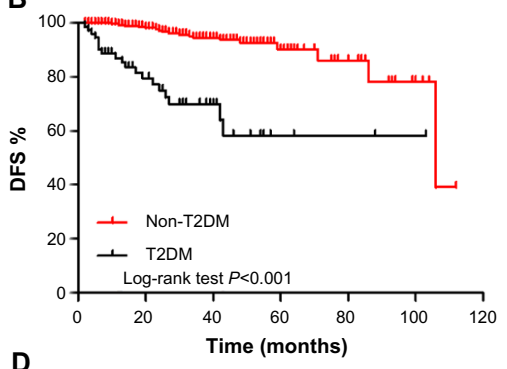

D

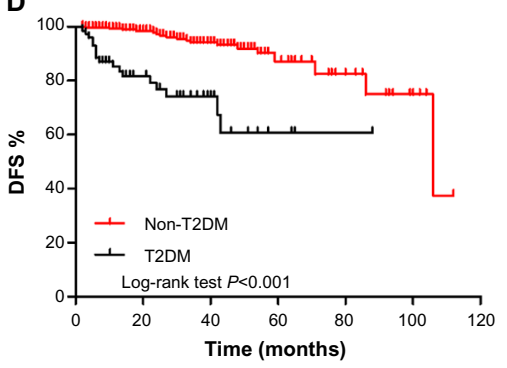

F

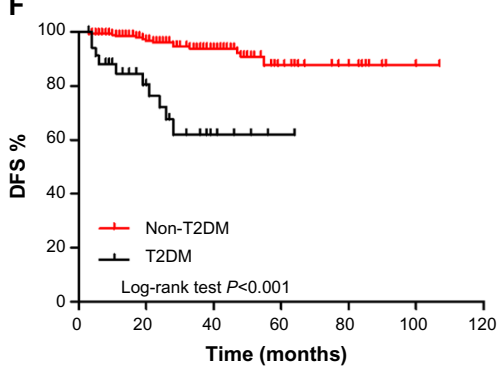

H

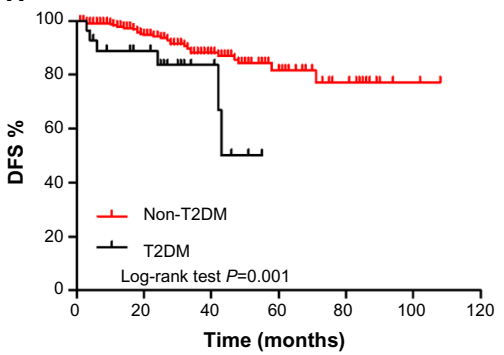

J

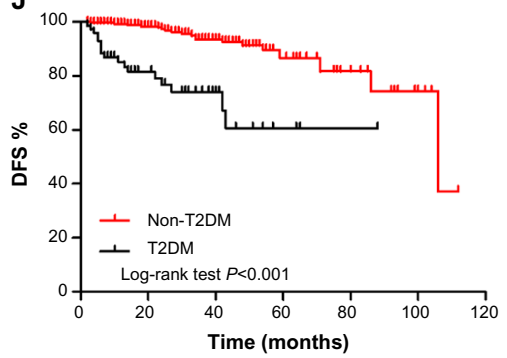

Figure 3 Kaplan-Meier estimates of DFS for TNBC patients between the non-T2DM and T2DM groups, according to age $\leq 50$ (A) and $>50$ (B), pre- (C) and postmenopausal (D), tumor size $\leq 5 \mathrm{~cm}(\mathbf{E})$ and $>5 \mathrm{~cm}(\mathbf{F})$, lymph node involvement negative $(\mathbf{G})$ and positive $(\mathbf{H})$, and minus (I) or plus (J) adjuvant chemotherapy. Abbreviations: DFS, disease-free survival; TNBC, triple-negative breast cancer; T2DM, type 2 diabetes mellitus.

The present study has several limitations that must be addressed. First, the association between T2DM and mortality was not discussed due to the following reasons: 1) all the patients included in the study had early stage disease; 2) preventive and treatment approaches are improving; 3) the follow-up time was relatively short (32.46 months), and most patients were enrolled after 2009, which may have limited the number of deaths observed; and 4) few of the participants died during the study period. The use of nationwide databases may have decreased the amount of missing data and the possibility of observational 
Table 4 Subgroup analysis of adjusted HR for DFS among TNBC patients with and without T2DM

\begin{tabular}{|c|c|c|c|}
\hline Subgroups & $P$-value & $\begin{array}{l}\text { HR (T2DM vs } \\
\text { non-T2DM) }\end{array}$ & $95 \% \mathrm{Cl}$ \\
\hline \multicolumn{4}{|l|}{ DFS } \\
\hline Age $\leq 50$ & 0.002 & 6.203 & I.957-19.656 \\
\hline Age $>50$ & $<0.001$ & 9.672 & $4.680-19.988$ \\
\hline Premenopausal & $<0.001$ & 8.742 & $3.224-23.700$ \\
\hline Postmenopausal & $<\mathbf{0 . 0 0 I}$ & 8.277 & $3.935-|7.4| \mid$ \\
\hline Tumor size $\leq 5 \mathrm{~cm}$ & $<0.001$ & 7.088 & $3.215-15.625$ \\
\hline Tumor size $>5 \mathrm{~cm}$ & $<0.001$ & 9.573 & $3.980-23.028$ \\
\hline $\begin{array}{l}\text { Negative lymph nodes } \\
\text { involvement }\end{array}$ & $<0.001$ & 19.086 & $7.7 \mid 2-47.232$ \\
\hline $\begin{array}{l}\text { Positive lymph nodes } \\
\text { involvement }\end{array}$ & $0.01 \mathrm{I}$ & 3.525 & I.329-9.344 \\
\hline Non-adjuvant chemotherapy & $<0.001$ & 8.742 & $3.224-23.700$ \\
\hline Adjuvant chemotherapy & $<0.001$ & 8.277 & $3.935-|7.4| \mid$ \\
\hline
\end{tabular}

bias. Additionally, the use of nationwide databases would prevent the selection bias that is inherent in single-institution studies. Although our study has some limitations, we shall focus more attention on early stage TNBC in future studies.

\section{Conclusion}

In conclusion, among Chinese patients with early stage TNBC, $\mathrm{T} 2 \mathrm{DM}$ is an independent prognostic risk factor that indicates a greater likelihood of recurrence and metastasis. T2DM should be considered when evaluating patients with early stage TNBC and choosing a treatment approach. Furthermore, early stage TNBC patients with T2DM require better therapeutic regimens. Controlling the factors that lead to a poor prognosis may improve the outcomes of patients with TNBC.

\section{Acknowledgment}

The authors thank the patients for their willingness to cooperate with our study.

\section{Author contributions}

All authors contributed toward data analysis, drafting and revising the paper and agree to be accountable for all aspects of the work.

\section{Disclosure}

This research is supported by grants from the National Natural Science Foundation of China (contract grant numbers: 81202080, 81302009, and 81201531) and the Shanghai Committee of Science and Technology Funds (contract grant numbers: 12ZR1442400, 12DZ2260100, 12ZR1406400,
12ZR1406200, and 1241010707700). The authors have declared that no other competing interests exist.

\section{References}

1. Hou G, Zhang S, Zhang X, Wang P, Hao X, Zhang J. Clinical pathological characteristics and prognostic analysis of 1,013 breast cancer patients with diabetes. Breast Cancer Res Treat. 2013;137(3): 807-816.

2. Kinne DW, Butler JA, Kimmel M, Flehinger BJ, Menendez-Botet C, Schwartz M. Estrogen receptor protein of breast cancer in patients with positive nodes. High recurrence rates in the postmenopausal estrogen receptor-negative group. Arch Surg. 1987;122(11):1303-1306.

3. Parl FF, Schmidt BP, Dupont WD, Wagner RK. Prognostic significance of estrogen receptor status in breast cancer in relation to tumor stage, axillary node metastasis, and histopathologic grading. Cancer. 1984;54(10):2237-2242.

4. Pichon MF, Broet $\mathrm{P}$, Magdelenat $\mathrm{H}$, et al. Prognostic value of steroid receptors after long-term follow-up of 2257 operable breast cancers. Br J Cancer. 1996;73(12):1545-1551.

5. Sorlie T, Tibshirani R, Parker J, et al. Repeated observation of breast tumor subtypes in independent gene expression data sets. Proc Natl Acad Sci U S A. 2003;100(14):8418-8423.

6. van't Veer LJ, Dai H, van de Vijver MJ, et al. Gene expression profiling predicts clinical outcome of breast cancer. Nature. 2002;415(6871): 530-536.

7. Sotiriou C, Neo SY, McShane LM, et al. Breast cancer classification and prognosis based on gene expression profiles from a population-based study. Proc Natl Acad Sci U S A. 2003;100(18):10393-10398.

8. Adeghate E, Schattner P, Dunn E. An update on the etiology and epidemiology of diabetes mellitus. Ann NY Acad Sci. 2006;1084:1-29.

9. Nolan JJ, O'Halloran D, McKenna TJ, et al. The cost of treating type 2 diabetes (CODEIRE). Ir Med J. 2006;99(10):307-310.

10. Larsson SC, Mantzoros CS, Wolk A. Diabetes mellitus and risk of breast cancer: a meta-analysis. Int J Cancer. 2007;121(4):856-862.

11. Larsson SC, Permert J, Håkansson N, Näslund I, Bergkvist L, Wolk A. Overall obesity, abdominal adiposity, diabetes and cigarette smoking in relation to the risk of pancreatic cancer in two Swedish populationbased cohorts. Br J Cancer. 2005;93(11):1310-1315.

12. Polesel J, Zucchetto A, Montella M, et al. The impact of obesity and diabetes mellitus on the risk of hepatocellular carcinoma. Ann Oncol. 2008;20(2):353-357.

13. Donadon V, Balbi M, Casarin P, Vario A, Alberti A. Association between hepatocellular carcinoma and type 2 diabetes mellitus in Italy: potential role of insulin. World J Gastroenterol. 2008;14(37):5695-5700.

14. Larsson SC, Andersson SO, Johansson JE, Wolk A. Diabetes mellitus, body size and bladder cancer risk in a prospective study of Swedish men. Eur J Cancer. 2008;44(17):2655-2660.

15. Liu X, Ji J, Sundquist K, Sundquist J, Hemminki K. The impact of type 2 diabetes mellitus on cancer-specific survival: a follow-up study in Sweden. Cancer. 2012;118(5):1353-1361.

16. Chen WW, Shao YY, Shau WY, et al. The impact of diabetes mellitus on prognosis of early breast cancer in Asia. Oncologist. 2012;17(4): 485-491.

17. Erickson K, Patterson RE, Flatt SW, et al. Clinically defined type 2 diabetes mellitus and prognosis in early-stage breast cancer. $J$ Clin Oncol. 2010;29(1):54-60.

18. Yancik R, Wesley MN, Ries LA, Havlik RJ, Edwards BK, Yates JW. Effect of age and comorbidity in postmenopausal breast cancer patients aged 55 years and older. JAMA. 2001;285(7):885-892.

19. Srokowski TP, Fang S, Hortobagyi GN, Giordano SH. Impact of diabetes mellitus on complications and outcomes of adjuvant chemotherapy in older patients with breast cancer. J Clin Oncol. 2009;27(13): 2170-2176.

20. Tammemagi CM, Nerenz D, Neslund-Dudas C, Feldkamp C, Nathanson D. Comorbidity and survival disparities among black and white patients with breast cancer. JAMA. 2005;294(14):1765-1772. 
21. Lipscombe LL, Goodwin PJ, Zinman B, McLaughlin JR, Hux JE. The impact of diabetes on survival following breast cancer. Breast Cancer Res Treat. 2008;109(2):389-395.

22. Jiralerspong S, Kim ES, Dong W, Feng L, Hortobagyi GN, Giordano SH. Obesity, diabetes, and survival outcomes in a large cohort of early-stage breast cancer patients. Ann Oncol. 2013;24(10):2506-2514.

23. Maiti B, Kundranda MN, Spiro TP, Daw HA. The association of metabolic syndrome with triple-negative breast cancer. Breast Cancer Res Treat. 2010;121(2):479-483.

24. Barone BB, Yeh HC, Snyder CF, et al. Long-term all-cause mortality in cancer patients with preexisting diabetes mellitus: a systematic review and meta-analysis. JAMA. 2008;300(23):2754-2764.

25. Du W, Simon MS. Racial disparities in treatment and survival of women with stage I-III breast cancer at a large academic medical center in metropolitan Detroit. Breast Cancer Res Treat. 2005;91(3):243-248.

26. Patterson RE, Flatt SW, Saquib N, et al. Medical comorbidities predict mortality in women with a history of early stage breast cancer. Breast Cancer Res Treat. 2010;122(3):859-865.

27. Peairs KS, Barone BB, Snyder CF, et al. Diabetes mellitus and breast cancer outcomes: a systematic review and meta-analysis. J Clin Oncol. 2011;29(1):40-46.

28. Davis AA, Kaklamani VG. Metabolic syndrome and triple-negative breast cancer: a new paradigm. Int J Breast Cancer. 2012;2012:1-10.

29. Coughlin SS, Calle EE, Teras LR, Petrelli J, Thun MJ. Diabetes mellitus as a predictor of cancer mortality in a large cohort of US adults. Am J Epidemiol. 2004;159(12):1160-1167.

30. Hemminki K, Li X, Sundquist J, Sundquist K. Risk of cancer following hospitalization for type 2 diabetes. Oncologist. 2010;15(6):548-555.

31. Hjartaker A, Langseth $H$, Weiderpass E. Obesity and diabetes epidemics: cancer repercussions. Adv Exp Med Biol. 2008;630:72-93.
32. Xue F, Michels KB. Diabetes, metabolic syndrome, and breast cancer: a review of the current evidence. Am J Clin Nutr. 2007;86(3): s823-s835.

33. Galea MH, Blamey RW, Elston CE, Ellis IO. The Nottingham Prognostic Index in primary breast cancer. Breast Cancer Res Treat. 1992;22(3):207-219.

34. Reed W, Hannisdal E, Boehler PJ, Gundersen S, Host H, Marthin J. The prognostic value of p53 and c-erb B-2 immunostaining is overrated for patients with lymph node negative breast carcinoma: a multivariate analysis of prognostic factors in 613 patients with a follow-up of 14-30 years. Cancer. 2000;88(4):804-813.

35. Carter CL, Allen C, Henson DE. Relation of tumor size, lymph node status, and survival in 24,740 breast cancer cases. Cancer. 1989;63(1): 181-187.

36. Rakha EA, El-Sayed ME, Green AR, et al. Prognostic markers in triplenegative breast cancer. Cancer. 2007;109(1):25-32.

37. Ewertz M, Jensen MB, Gunnarsdóttir KÁ, et al. Effect of obesity on prognosis after early-stage breast cancer. J Clin Oncol. 2011;29(1): 25-31.

38. Berclaz G, Li S, Price KN, et al; International Breast Cancer Study Group. Body mass index as a prognostic feature in operable breast cancer: the International Breast Cancer Study Group experience. Ann Oncol. 2004;15(6):875-884.

39. Goodwin PJ, Ennis M, Pritchard KI, et al. Fasting insulin and outcome in early-stage breast cancer: results of a prospective cohort study. J Clin Oncol. 2002;20(1):42-51.

40. Ademuyiwa FO, Groman A, O'Connor T, Ambrosone C, Watroba N, Edge SB. Impact of body mass index on clinical outcomes in triplenegative breast cancer. Cancer. 2011;117(18):4132-4140.
OncoTargets and Therapy

\section{Publish your work in this journal}

OncoTargets and Therapy is an international, peer-reviewed, open access journal focusing on the pathological basis of all cancers, potential targets for therapy and treatment protocols employed to improve the management of cancer patients. The journal also focuses on the impact of management programs and new therapeutic agents and protocols on

\section{Dovepress}

patient perspectives such as quality of life, adherence and satisfaction The manuscript management system is completely online and includes a very quick and fair peer-review system, which is all easy to use. Visit http://www.dovepress.com/testimonials.php to read real quotes from published authors. 